\title{
Managerial Decision Making and Changing Prices: The Effects of Inflation on Internal Information and Operating Policies
}

\author{
Thomas E. King \\ and \\ M. Robert Carver \\ Department of Accounting \\ Southern Illinois University \\ Edwardsville, Illinois
}

The accounting assumption of a stable measuring unit generally has allowed accountants to ignore the changing value or purchasing power of the dollar in preparing external accounting reports. Nevertheless, the issue of whether or not financial statements should be adjusted to reflect changing prices of either the specific or general variety has been of concern for many decades. With the higher inflation rates of the late seventies and early eighties, the validity of the stable-measuring-unit assumption has been a topic of frequent debate; and the entire issue of accounting for the effects of changing prices has gained in relevance.

In 1979, the Financial Accounting Standards Board issued FASB Statement No. 33 (4) requiring that large public enterprises disclose the effects of changing prices as supplementary information to published financial statements prepared on an unadjusted basis. The pronouncement originally required that supplementary income summaries be computed and disclosed on both a "constant dollar" and a "current cost" basis. Constant dollar reporting states the financial statement elements in dollars of the same general purchasing power. Current cost reporting states financial statement elements at what their costs would be at the balance sheet date to the time of their use. In 1984, the FASB issued Statement No. 82 (5) eliminating the requirement for constant dollar reporting under certain conditions.

SFAS No. 33 applies to all public companies which prepare their financial statements in U.S. dollars in accordance with U.S. generally accepted accounting principles and which have either total assets of more than $\$ 1$ billion or inventories and gross plant, property, and equipment of more than $\$ 125 \mathrm{mil}$ lion at the beginning of the current fiscal year. The amounts for these criteria are the amounts shown in the company's consolidated financial statements.

While SFAS No. 33 placed certain requirements on particular companies with regard to their external reporting, internal reporting is not so constrained. Managements continue to be free to choose what they consider to 
be the most appropriate information sets for internal decision making without the interference of external bodies such as the FASB or SEC. Therefore, if, as the literature suggests, the effects of changing prices are important in managerial decision making, managers should incorporate adjustments for changing prices in the information that they use for internal purposes, regardless of any requirements established to regulate external reporting. Especially when considering long-tern projects, managers could be expected to consider the cumulative effects of inflation over the lives of projects and the possible impact of changing rates of inflation.

\section{Purpose of the Study}

The purpose of this study is to examine the extent to which the effects of changing prices are incorporated into managerial decision making and the extent to which the inclusion of such effects is associated with increasing rates of inflation and the issuance of SFAS No. 33.

The studies to date generally have been concerned either with (1) describing why the effects of changing prices should be incorporated into managerial decisions and how this might be done or (2) reporting and compliance problems associated with implementing SFAS No. 33 for external reporting and the anticipated reactions of external users to financial data adjusted for changing prices (see, for example, 1, 2, 6, 8, 9). Hawkins (7), however, suggests that there will also be a significant impact of SFAS No. 33 on the internal actions of managers in their attempts to influence the financial statement information required under SFAS No. 33. His expectation is that internal managers take different actions when required to present external reports adjusted for changing prices.

There could also be another effect related to the issuance of SFAS No. 33. If certain firms are required to present information adjusted for changing prices for external purposes, that information is available for internal decision making at no additional cost. Thus, the SFAS No. 33 requirements may have provided the impetus to begin using the same information internally.

While most studies relating to SFAS No. 33 and adjustments for changing prices deal with external reporting, there are three that are concerned specifically with internal reporting and decision making. Casey ard Sandretto (3) look at the internal reporting practices of Fortune 500 companies with respect to inflation-adjusted accounting information. Rosenzweig (11) focuses specifjcally on SFAS No. 33 data and how they are used internally for decisions. The results of these two studies seem to conflict somewhat in that Casey and Sandretto find that nearly half of the companies responding to their survey report inflation-adjusted data internally, while Rosenzweig finds little internal reporting and little internal use of SFAS No. 33 information. It should be noted that Casey and Sandretto's study deals with all types of inflation adjusted data, not just that prepared in accordance with SFAS No. 33; and it concerns only whether the data is reported internally, not whether the data 
actually is used. Further, they found greater reporting of inflation-adjusting data to top management than to operating management.

In a study of Canadian companies, Waterhouse (13) reported that less than six percent of the respondents indicated that inflation-adjusted financial reports were prepared for use by management and that the vast majority of Canadian managers saw little advantage to the use of such data for internal decision- making purposes. This result might be expected if, in fact, an external reporting requirement such as SFAS No. 33 does promote the internal use of the data. Currently, there is no requirement in Canada similar to SFAS No. 33 requiring external accounting reports to include information that is adjusted for changing prices.

This study is concerned with the degree to which inflation-adjusted data are incorporated into managerial decisions in the United States, the extent to which that phenomenon has been associated either with high rates of inflation or the issuance of SFAS No. 33, and the specific types of decisions for which inflation-adjusted data have been used. In addition, the study examines the relationship between several attributes of the firms surveyed and the use of inflation-adjusted data for internal decision making. For the manufacturing firms surveyed, these attributes include the size of the firm and the type of industry. For financial institutions, size, type of institution, and geographical location were identified as potentially important variables.

\section{Methodology}

The study involved three related stages. First, an examination was made of the relevant accounting and economics literature to identify those decision areas that should be most affected by changing prices. Second, selected audit managers with major public accounting firms, and financial managers with several industrial firms and financial institutions were interviewed to further help identify decision areas that would be most affected by changing prices. In addition, these managers helped identify company attributes that were expected to be related to the use of inflation-adjusted information. Third, based upon the results of the first two stages of the study, a questionnaire was developed and sent to financial and operating officers of major corporations and financial institutions.

The questionnaire focused upon the decision areas previously identified as most likely to be affected by changing prices. Some of the areas explored in the questionnaire include: capital budgeting and investments in fixed assets, investments in inventory, evaluation of managers, credit decisions and policies, and financing decisions. The questionnaire asked managers to describe the way in which the effects of changing prices were incorporated into their decisions in each of the various decision areas and how long these approaches had been used be the company. Also, the managers were asked to specify whether their companies reported external accounting information in accordance with FASB Statement No. 33 and, regardless of the external reporting requirement, whether the pronouncement had any effect on their internal re- 
porting. The survey was conducted immediately prior to the issuance of FASB Statement No. 82 so that any impact of FASB Statement No. 33 would be reflected in the data, but not any effects of FASB Statement No 82 .

The questionnaire was mailed to 1,000 chief financial and operating officers of companies that were divided equally between industrial firms and financial institutions. The industrial firms, selected at random, were from a broad range of industries (e.g., manufacturing, retailing, real estate) and included small, medium, and large firms. Small firms were defined as having sales of less than $\$ 10$ million; medium-sized firms, sales of between $\$ 10$ million and $\$ 100$ million; and large-sized firms, sales over $\$ 100$ million. Financial institutions surveyed included commercial banks, mutual savings banks, and savings and loan associations. The size classifications for financial institutions were defined as follows: small, deposits of less than $\$ 1$ million; medium, deposits of between $\$ 1$ million and $\$ 500$ million; and large, deposits of over $\$ 500$ million.

The overall response rate to the questionnaire was 22 percent. A second mailing of the questionnaire was made for both types of firms, and no significant differences were found between the results of the first and second mailings.

Of the companies responding to the survey, 33 percent of the manufacturing and trading firms prepare external accounting reports in conformity with SFAS No. 33, while 44 percent of the financial institutions prepare such reports.

\section{Results of the Study}

This study is somewhat broader than the three previous studies dealing with internal reporting of inflation-adjusted data in that it looks at the impact of SFAS No. 33 data as well as the use of other types of data adjusted for changing prices. In addition, the study looks at the impact of inflation itself on the decisions of firms in the study. Further, this study found that the use of inflation-adjusted data for internal decision making is related in a few cases to certain company attributes; and these attributes are noted where the relationship is statistically significant (at the .05 level unless otherwise indicated).

\section{Use of Inflation-adjusted Information}

Of the manufacturing firms responding to the survey, well over half of the firms use inflation-adjusted data in some way for internal decision making. The type of data, the extent of the usage, and the way in which the data are used differs considerably with individual firms. Table 1 summarizes the responses of manufacturing firms in the sample by the type of use of inflationadjusted data.

Current cost data are used by 87 percent of the manufacturing and trading firms in computing costs of production and operation, excluding depreciation. Almost two-thirds of the manufacturing and trading firms use some type of inflation-adjusted information in capital budgeting decisions, and half of the firms use such information in pricing their goods. Inflation-adjusted is 
Table 1

Internal Uses of Inflation-adjusted Data

Manufacturing Firms

\section{Type of Use}

Evaluating expected revenues from capital projects

63

Evaluating expected costs associated with capital projects

Evaluating desired rate of return on capital projects

Stating most dollar performance goals and objectives of managers

Making comparisons between budgeted amounts and actual results

Pricing goods

50

Computing materials and other input costs of productions

Computing depreciation for calculating production costs 
used by this group of forms to a lesser extent in performance evaluation of managers, although 36 percent did report using such data in stating most dollar performance goals and objectives of managers and 25 percent in making comparisons between budgeted and actual amounts.

Interestingly, the use of inflation-adjusted data by the manufacturing and trading firms responding affirmatively was not a recent phenomenon. In each case, more than half of the firms using inflation-adjusted data for the purpose indicated had been doing so since prior to the issuance of SFAS No. 33.

Even though the percentage of financial institutions preparing external accounting reports in conformity with SFAS No. 33 was higher than that for the manufacturing firms responding, the financial institutions seem to use inflation-adjusted data to a lesser extent internally. Table 2 shows the percentage of the financial institutions in the survey indicating that they use inflation-adjusted data in the ways listed. With two notable exceptions, the percentage of financial institutions employing inflation-adjusted data for the various individual uses listed ranges between 16 and 21 percent. Almost none of the financial institutions used inflation-adjusted data for performance evaluation, either in terms of stating managers' goals and objectives or making comparisons between budgeted and actual amounts. This result is in contrast to the findings for the manufacturing firms, which indicate that at least onethird of those firms use inflation-adjusted data in some way for performance evaluation, even though that is the least frequent use of such data of those listed.

As compared with the length of time that the manufacturing and trading firms had been using inflation-adjusted data, the financial institution respondents that were using such information adopted the practice fairly recently. Well over half of the financial institutions had adopted their particular use of inflation-adjusted data within the previous five years, or since SFAS No. 33 was issued.

\section{Characteristics of the Respondents}

Overall, no general pattern of relationship between the internal use of inflation-adjusted data and the chosen company's attributes of the respondents was found. However, a significant relationship was found with respect to several of the specific uses of inflation-adjusted data. For example, different types of companies reflected different usage of inflation-adjusted data for budget comparisons, with real estate, manufacturing, construction, and wholesale companies reporting significantly higher usage of such data than did other types of companies.

Size of the firm was found to be a significant variable with respect to the use of current costs in computing depreciation for internal reporting. Surprisingly, smaller firms were found to use current cost depreciation internally significantly more often than larger firms; and this was true for both manufacturing companies and financial institutions.

For financial institutions, the type of institution and geographical location were found to be significant in some cases. With regard to evaluating expected 
Internal Uses of Inflation-adjusted Data

Financial Firms

Type of Use

Percent Responding

Yes No

Evaluating expected revenues from:

Consumer and Mortgage Loans

Commercial loans

Acquisition of bank or assoc. property

Evaluating expected expenses related to

Consumer and mortgage loans

Commercial loans

Acquisition of bank or assoc. property

Evaluating desired rate of return from:

Consumer and mortgage loans

Commercial loans

Acquisition of bank or assoc. property

Stating performance goals and objectives of managers or officers

Making comparisons between budgeted amounts and actual results

Computing depreciation for calculating operating costs 
expenses relating to consumer and mortgage loans, most of the savings and loan associations ( $83 \%)$ indicated that the data they used were not adjusted for inflation. On the other hand, a majority of commercial banks $(55 \%)$ indicated that they did use inflation-adjusted data. Similarly, in setting loan rates, use of inflation-adjusted data was highest among commercial banks $(26 \%)$ and lowest among savings banks (3\%).

Geographical location was found to be related to the use of inflationadjusted data by financial institutions in evaluating both expected revenues and expected expenses. The results of the study indicate that financial institutions outside of the south are more likely to use inflation-adjusted data for this purpose than firms in the south. More specifically, inflation-adjusted data were used by $83 \%$ of the firms in the midwest, $67 \%$ of those in the west, and $53 \%$ of those in the northeast; only $22 \%$ of the firms in the southeast and $17 \%$ of those in the southwest used inflation-adjusted data for evaluating expected revenues and expected expenses.

Impact of SFAS No. 33

Tables 3 and 4 summarize the responses for the manufacturing/trading firms and financial institutions, respectively, indicating the impact of SFAS No. 33 on each of several internal reporting and decision areas. The questions in this part of the survey have a somewhat narrower focus than those in the previous section; these questions deal only with the effects of SFAS No. 33 rather than with all types of inflation-adjusted data.

On a percentage basis, considerably more manufacturing and trading firms were impacted internally by SFAS No. 33 than financial institutions. In fact, SFAS No. 33 seems to have impacted very few financial institutions internally. The areas most affected for both types of firms are (1) evaluation of capital projects and (2) budgeting and goal-setting.

The impact of SFAS No. 33 on budgeting and goal-setting is somewhat surprising given that this area is one where both types of firms were least likely to use inflation-adjusted data. One explanation for the apparent discrepancy might be that inflation-adjusted data are not used for stating most performance goals, which is how the question was worded, but are used at higher management levels for goal-setting. This explanation would be consistent with Casey and Sandretto's findings that top management received inflation-adjusted data more frequently than operating management. Another explanation might be that, while management does not use inflation-adjusted data to a large extent in goal-setting, SFAS No. 33 does impact the budgeting and goal-setting, as Hawkins (7) suggested, because managers take different actions when required to present external reports adjusted for changing prices.

\section{Operating Policies in Response to Inflation}

This section of the survey is somewhat different form the other sections in that it deals with operating policies rather than different types of information. Tables 5 and 6 show the extent to which the manufacturing/trading firms and the financial institutions in the sample, respectively, have adopted the listed operating policies in response to inflation. Nearly all of the firms in the survey 
Internal Reporting and Decision Areas Affected by FASB Statement No. 33 Manufacturing Firms

Area

Financial Ratios

Profits or costs by responsibility center, product, or type of operation

Evaluation of capital projects

Budgeting and goal setting

Performance evaluation

Other
Percent Responding Yes No

87

Table 4

Internal Reporting and Decision Areas Affected by FASB Statement No. 33

Financial Firms

Percent Responding

Area

Financial Ratios

6

94

Profits or costs by responsibility center or type of operation

Evaluation of capital projects or long-term investments

Budgeting and goal setting

Performance evaluation 
have made at least some changes in operating policies because of inflation. Most firms in the sample have taken multiple actions.

Almost all of the firms responding, both manufacturing/trading and financial, have reduced idle cash balances; and a considerable majority have tightened credit and/or collection policies. For manufacturing/trading firms, the reduction of idle cash balances was related to the size of the firm. Overall, more of the larger firms had reduced idle cash balances; and they had been doing it for a longer time than the smaller firms. With respect to financial institutions, the tightening of credit and/or collection policies was found to be related to the type of institution. This action had been taken most often by savings and loan associations and least often by commercial banks. For those commercial banks that did take this action, however, $76 \%$ did so in 1982 or before, while $40 \%$ of the savings and loans indicated that the action had been taken since 1982. Perhaps this result partially explains the serious plight of many savings and loans currently.

Most manufacturing firms were found to have been buying inventories earlier to avoid price increases, increasing the amount of time before paying suppliers, and increasing the use of fixed dollar contracts and/or debt financing arrangements. Nearly half of the manufacturing firms have decreased the required payback period for new capital projects.

Nearly all of the financial institutions responding have decreased their long-term fixed-rate lending, and most have shortened the required maturity for new loans. The type of financial institution most frequently indicating a reduction in required maturity for loans was savings and loan associations. This result might be expected given the impact of inflation on the type of longterm lending normally done by savings and loans. However, almost half of the savings and loans indicate that they have decreased maturities only since 1982 , indicating a rather late response to a serious problem. Interestingly, only about a quarter of the financial institutions responding have increased their long-term fixed-rate borrowing.

\section{Summary and Conclusions}

The results of this study indicate that quite a number of companies use inflation-adjusted information to at least some extent in internal reporting and decision making. This tends to be true more for the manufacturing/trading firms in the sample than for the financial institutions. Many firms that currently are using inflation-adjusted data started doing so prior to the issuance of SFAS NO. 33, although most financial institutions that use such data internally started doing so after the effective date of the pronouncement. Overall, the issuance of SFAS No. 33 appears to have had only a small impact on the use of inflation-adjusted data internally, probably less of an impact than the high inflation rates of the late seventies. 
Operating Policies Undertaken in Response to Inflation Manufacturing Firms

\section{Operating Policy}

Buy inventories earlier to avoid higher prices later

Increase use of fixed dollar contracts and/or debt financing arrangements

Tighten credit and/or collection policies

Increase amount of time before payment is made to suppliers

Shorten the required payback period for capital projects

Table 6

Operating Policies Undertaken in Response to Inflation Financial Firms

\section{Operating Policy}

Increase the portion of borrowing done through long-term fixed-rate arrangements

Tighten credit and/or collection policies

Reduce idle cash balances

Shorten required maturity for new customer loans

Decrease the portion of long-term fixed-rate lending

Percent Responding

Yes No

5

6 


\section{References}

1. Arthur Andersen \& Co. Inflation Accounting-A Simplified Approach: Reporting the Impact of Inflation from a New Perspective, Arthur Andersen \& Co., 1980.

2. Berlinger, Robert W. and Gerboth, Dale L. "FASB Statement No. 33, 'The Great Experiment,"'Journal of Accountancy, May 1980, 48-54.

3. Casey, C. J. and Sandretto, M. J. "Internal Uses of Accounting for Inflation," Harvard Business Review, November-December 1981, 149-156.

4. Financial Accounting Standards Board. Statement of Financial Accounting Standards No. 99, "Financial Reporting and Changing Prices," September 1979.

5. Financial Accounting Standards Board. Statement of Financial Accounting Standards No. 82, "Financial Reporting and Changing Prices: Elimination of Certain Disclosures," November 1984.

6. Hawkins, David F. Inflation, Market Efficiency and Accounting Data: Key to Identifying the Corporate and Investor Winner, Boston: Drexel Burnham Lambert Inc., May 1974.

7. Hawkins, David F. "Thinking Real: Living with FASB 33," Harvard Business Review, September-October 1980, 119-127.

8. Hayes, Robert H. and Abernathy, William J. "Managing Our Way to Economic Decline," Harvard Business Review, July-August 1980.

9. Lembke, Valdean C. "Replacement Costs: An Analysis of Financial Statement and Tax Policy Effects," Journal of Accounting, Auditing and Finance, Winter 1980, 147-162.

10. Raiborn, Debra D. and Ratcliffe, Thomas A. "Are You Accounting for Inflation in Your Capital Budgeting Process?" Management Accounting, September 1979, 19-22.

11. Rosenzweig, Kenneth. "Companies Are Not Using FAS 33 Data," Managemer Accounting, April 1985, 51-57.

12. Scott, George M.Research Study on Current-Value Accounting Measurements and Utility, Touche Ross Foundation, 1978.

13. Waterhouse, J.Reporting Non-Historical Accounting Data to Canadian Managers. Study Paper No. 5, Edmonton, Canada: Canadian Certified General Accountants' Research Foundation, May 1984. 